\title{
AEROBIC FITNESS TREND OF STUDENTS OF THE FACULTY OF SPORT AND PHYSICAL EDUCATION AT THE UNIVERSITY OF BELGRADE
}

\author{
Goran Prebeg* \\ Faculty of sport and physical education, University of Belgrade, Serbia \\ Natalija Mihajlović \\ Bachelor of Sport, Belgrade, Serbia \\ Dušan Mitić \\ Faculty of sport and physical education, University of Belgrade, Serbia
}

\begin{abstract}
Aerobic fitness, endurance, and cardiovascular endurance are synonyms for work capacity, which itself is an important prerequisite for the health and life of every man. The purpose of this research was to identify the trend of aerobic fitness of students in the last 15 years. The Survey method, which implies nonexperimental crossectional research, was used. The instrument is UKK $2 \mathrm{~km}$, walking test. The total sample consisted of 605 subjects ( 389 males, 216 females), students of Faculty of Sport and Physical Education, aged 18-28 years. They were divided into three groups, according to when they were tested, the first group was tested in the period 1997-2000 $(\mathrm{N}=299)$, the other was tested from 2001-2004 $(\mathrm{N}=200)$, the third was tested in $2012(\mathrm{~N}=106)$. Analysis of the results showed a decreasing trend in fitness index of male students with 104.1 to 77.3 , and of the female students from 96.4 to 84.8. T-tests confirmed differences in fitness index, at the level of $\mathrm{p}<0.05$ for both sexes. The maximum oxygen consumption among male students declined from 51.3 to $40.3 \mathrm{ml} / \mathrm{kg} / \mathrm{min}$, and among female students from 37.5 to $33.7 \mathrm{ml} / \mathrm{kg} / \mathrm{min}$. The results indicate toward decreasing trend in students' aerobic fitness in both sexes, but the trend is less pronounced in female students. Students of both sexes have fitness index values below the standard norms of the Swedish population. According to the criteria of Cooper oxygen consumption students have moved from the "Excellent" to the "Very good" category. The general trend of decreasing aerobic fitness of the population can be seen in the sport and physical education students, as a consequence of lifestyle in which there is not enough adequate physical activity.
\end{abstract}

Keywords: students, UKK 2 miles, fitness level

\footnotetext{
${ }^{*}$ Corresponding author. Faculty of Sport and Physical Education, University of Belgrade, Blagoja Parović 156, 11030 Belgrade, Serbia, e-mail: goran.prebeg@fsfv.bg.ac.rs
} 


\section{Introduction}

A number of studies point to the key role of physical activity in order to ensure proper physical and mental growth and development, environmental health, improvement of working capacity and quality of life. For it is precisely through physical activity, the development of aerobic fitness, or cardiovascular endurance important prerequisite.

However, despite the large number of information available on the various benefits of physical activity in general, remain the most vulnerable people such as children, adolescents, persons exposed to stressful situations, and the elderly. If we consider only the categories of adolescents, this group, in addition to high school age, and belong to the students as well as older adolescents. Study represents a significant change in lifestyle, the qualitative organization of learning, and frequently change their place of residence. Adolescents, the majority, have stabilized work habits, social behavior in the area are still searching for their own identity and self-affirmation. The way of life is such that there is not enough physical activity, with great psychological stress, especially during exam preparation. On the other hand, modern lifestyles and modern technologies contributing to spare the man from physical strain and fatigue, but denied physical activity. Leisure is becoming a victim of this technology, in which all forms of communication and movement to the use of its products (Mitić, 2001).

At universities in Serbia, in the period between 1963 to 1998, regular physical education classes for all first year students were organized. In addition, a number of recreational activities was offered at nearby resorts. However, repeated testing of students from the Faculty of sport and physical education in Belgrade, using the Cooper UKK test brisk walking $2 \mathrm{~km}$, known in the literature as a test to assess aerobic endurance (Laukkanen, 1992), indicated a declining trend in aerobic capacity, as a result of less physical activity.

\section{Method}

Testing was performed on the total sample of 605 subjects (389 males, 216 females), aged 18 to 28 years, all of them being students of Faculty of Sport and Physical Education in Belgrad. They were divided into three groups, in relation to the period when they were tested.

The first group was tested in the period 1997-2000, $\mathrm{N}=299$, the second group was tested from 2001-2004, $\mathrm{N}=200$, and a third group 2012th years, $\mathrm{n}=106$ th. To extract and analyze the results the Survey method was used, ie. a nonexperimental cross-sectional research. Statistical analysis comprised the Student t-test, commonly-used parametric test of significance to test the null hypothesis (Cvetković, 2009).

The instrument applied in this study was UKK $2 \mathrm{~km}$, a brisk walking test, according to Dr. Kenneth Cooper, the $2 \mathrm{~km}$ long track. It is intended for testing of healthy adults aged 18 to 65 years. The test is relatively simple and does not require complex research skills. It is generally performed under field conditions, allows simultaneous usage on many subjects, and is quite reliable when it comes to testing non-atletes. Walking is an activity that engages the large muscle groups, it is safe, low-risk activity that doesn't lead to the rapid fatigue. Before preparation for the test, subjects complete a standardized questionnaire dealing with their daily physical activity habits, leisure time physical activity or physical activity at the workplace, organized forms of sport or recreation in which they participate, possession of sports equipment, and satisfaction with their level of physical activity. Then the respondents height and weight were measured, by anthropometer and digital scale, respectively, so to get information on the percentage of muscle and fat tissue in the body. 
The aerobic fitness test applied, known as aerobic endurance test, is based on an indirect estimate of maximum oxygen consumption, which forms the basis of physical work capacity. Test protocol demands respect for outside air temperature in the range of $5-25^{\circ} \mathrm{C}$, moderate humidity, loose-fitting clothing, and warm-up 5 - 10 minutes prior to testing (stretching the muscles of the legs and spine, brisk walking about 200 meters).

After completion of brisk/vigorous two miles walk on the clean and flat track, the walking time and heart rate are recorded. Precise test performance enables determination of fitness index (general fitness), as well as estimation of indirect maximum oxygen consumption, calculating BMI (body mass index) and the possibility of calculating the energy input required calories per day in relation to body composition (Ksale / KJ) .

Walking test was performed on the total sample of 605 subjects, aged 18 to 28 years, who are students FSFV in Belgrade, that is 389 male students and 216 female students. They were divided into three groups, in relation to the period when they were tested. The first group was tested in the period 1997-2000, $\mathrm{N}=299$, the second group was tested from 2001-2004, $\mathrm{N}=200$, and a third group 2012th years, $\mathrm{n}=106 \mathrm{th}$.

The goal of this research was to compare mean values of fitness index and maximal oxygen consumption (VO2 max) of three groups of subjects. The t-test examined whether there were statistically significant differences between groups in Fitness index and maximal oxygen consumption.

Testing was performed according to the protocol, and the data processed by the appropriate formulas. Fitness formula for calculating the index of the people aged 18 to 65 years (Stojiljković, Mitić, Mandarić, \& Nešić, 2005):

Men $=420-(11.6 \mathrm{~min}+0.2 \mathrm{sec}+0.56 \mathrm{HR}+2.6 \mathrm{BMI})+0.2$ years

Women $=304-(8.5 \mathrm{~min}+0.14 \mathrm{sec}+0.32 \mathrm{HR}+1.1 \mathrm{BMI})+0.4$ years

Achieved time in minutes and seconds (eg, 15: 30 is split into $15 \mathrm{~min}$ and $30 \mathrm{sec}$ ),

HR - heart rate at the end of the test within one minute;

BMI-weight $(\mathrm{kg}) /$ height $(\mathrm{m})$ squared,

The age of patients .

Table 1.

Categories according to FITNESS INDEX

Obtained values of FITNESS INDEX

$<70$ well below the average

$70-89$ somewhat below average

$90-110$ average

110 - 130 something above average

$>130$ well above average

FITNESS INDEX is the fitness level of the person from the test, compared with the average level of people the same age and sex, was calculated based on walking time, heart rate, body weight index and age. FITNESS INDEX 100 corresponds to an average maximum oxygen consumption between genders, individuals and years. Values below 100 presents a below average level of fitness, a value above which fitness levels are above average. The formula for calculating the maximal oxygen uptake $-\mathrm{VO}_{2 \max }(\mathrm{ml} / \mathrm{min} / \mathrm{kg})$ : 


$$
\begin{aligned}
& \text { Men }=\mathrm{VO}_{2} \max =184.9-4.65 \text { time }-0.22 \mathrm{HR}-0.26 \text { years }-1.05 \mathrm{BMI} \\
& \text { Women }=\mathrm{VO}_{2} \max =116.2-2.98 \text { time }-0.11 \mathrm{HR}-0.14 \text { years }-0.39 \mathrm{BMI}
\end{aligned}
$$

Recorded time of test execution is translated as follows: $15 \mathrm{~min}$ and $30 \mathrm{sec}=15.5 \mathrm{~min}$ predicted $\mathrm{VO}_{2 \max }$ is the estimated consumption of $\mathrm{VO}_{2 \max }(\mathrm{ml} / \mathrm{min} / \mathrm{kg})$ calculated on the basis of time walking, heart rate, body weight index and age. The value of maximum aerobic capacity is presented in Table 4. and 5. Predicted HR max is the highest heart rate that can be achieved by testing, and estimated based on oxygen consumption and heart rate during a walk in the test. Maximum heart rate can be used to determine the person's target zone, with recommendations for further training.

Table 2 .

The maximum aerobic capacity $\mathrm{VO}_{2} \max (\mathrm{ml} / \mathrm{min} / \mathrm{kg})-\mathrm{men}$

\begin{tabular}{cccccc}
\hline Age & Decreased & Insufficient & Average & Good & Excellent \\
\hline $20-29$ & $<25$ & $25-33$ & $34-42$ & $43-52$ & $>53$ \\
$30-39$ & $<23$ & $23-30$ & $31-38$ & $39-48$ & $>49$ \\
$40-49$ & $<20$ & $20-26$ & $27-35$ & $36-44$ & $>45$ \\
$50-59$ & $<18$ & $28-24$ & $25-33$ & $34-42$ & $>43$ \\
$60-69$ & $<16$ & $16-22$ & $23-30$ & $31-40$ & $>41$ \\
\hline
\end{tabular}

Table 3.

The maximum aerobic capacity $\mathrm{VO}_{2} \max (\mathrm{ml} / \mathrm{min} / \mathrm{kg})-$ women

\begin{tabular}{cccccc}
\hline Age & Decreased & Insufficient & Average & Good & Excellent \\
\hline $20-29$ & $<24$ & $24-30$ & $31-37$ & $38-48$ & $>49$ \\
$30-39$ & $<20$ & $20-27$ & $28-33$ & $34-44$ & $>45$ \\
$40-49$ & $<17$ & $17-23$ & $24-30$ & $31-41$ & $>42$ \\
$50-59$ & $<15$ & $15-20$ & $21-27$ & $28-37$ & $>38$ \\
$60-69$ & $<13$ & $13-17$ & $18-23$ & $24-34$ & $>35$ \\
\hline
\end{tabular}




\section{Results}

Data for the fitness index and maximal oxygen consumption (average value), particularly for women and men, in relation to the period when they were tested, are shown in the lower part of Figure 1. and 2.

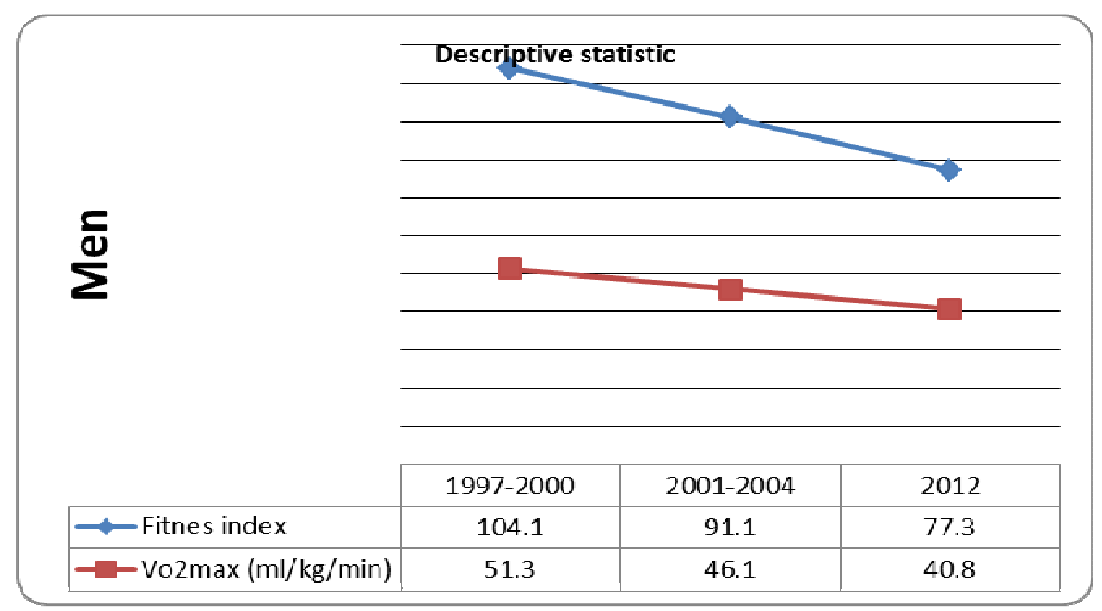

Figure 1. Fitness index and VO2max for men

On Figure 1. the results show that the index of the first tested fitness group (1997-2000) is 104.1, which according to Swedish population norms is within the average range of the index (90-110). In the second group the index is 91.1 , which is slightly lower than the previously tested group, but still within the average values. In the third group (2012) Fitness index is 77.3, which is lower than the both previously tested groups, and according to the Swedish population norms this value falls into the category of 'somewhat below average' (70-89). Figure 1 presents the mean maximal oxygen uptake, VO2max, in which also noted a downward trend. In the first group, the average value of VO2 max was 51.3, 46.1 in the second. Both of these values, according to Cooper's maximal aerobic capacity norms $(\mathrm{ml} / \mathrm{min} / \mathrm{kg}$ ), are above the average category. In the third group, VO2max value is 40.8 , which is the average value.

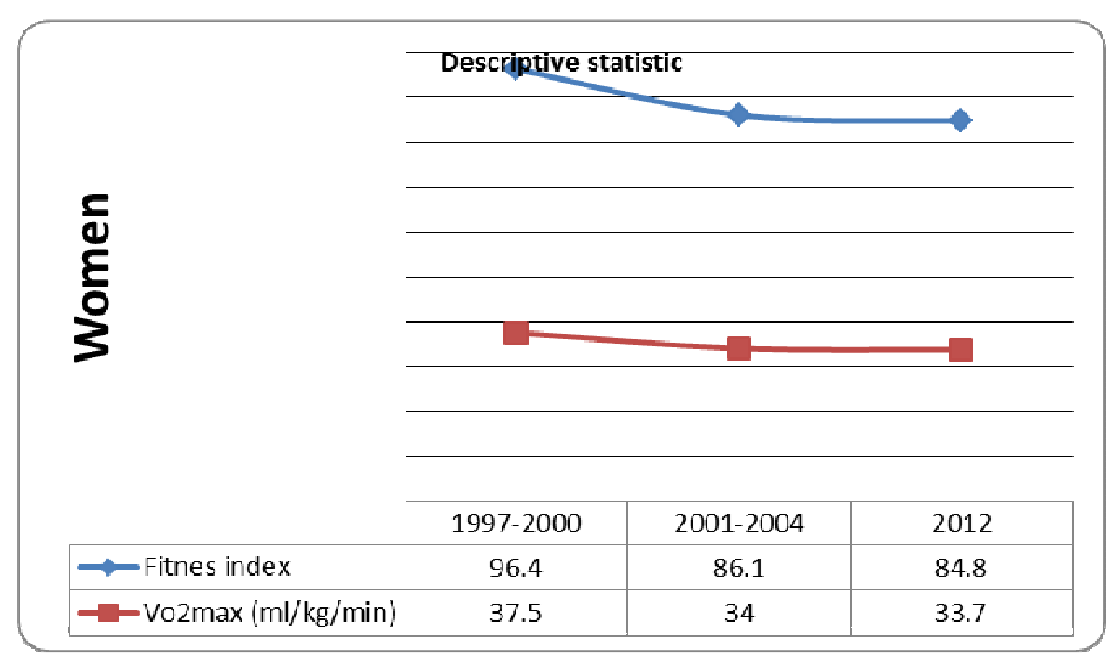

Figure 2. Fitness index and VO2max for women 
Figure 2 shows that in women there is a declining trend in Fitness Index, with the first group (1997-2000) average value of 96.4, which is the average index value, according to the Swedish population norms. In the second group (2001-2004) index is 86.1, while the third group (2012) achieved index value of 84.8. Index values in the second and third group fall into the category of 'somewhat below average."

According to Figure 2, showing the average values of maximum oxygen consumption in women, the first group scored 37.5, second group - 34, and third group - 33.7. All three values are within the average category, according to the criteria of the Cooper oxygen consumption. $\mathrm{T}$ test showed a statistically significant differences for both sexes.

\section{Conclusions}

The aim of this study was to compare the fitness index and maximal oxygen consumption between three groups tested with Coopers brisk walking test on the path of $2 \mathrm{~km}$. The participants where students of the Faculty of Sport and Physical Education, which have been tested over the last fifteen years, in the period from 1997-2000, the first group, 2001-2004, the second group, and 2012. the third group. Testing was performed by the same protocol in similar conditions. Number of subjects tested 1997-2000 is approximately equal to the number of subjects tested, 2001-2004, while the number of subjects tested 2012th was slightly smaller. As for the number of subjects divided by sex, more male subjects were tested, while in the age category all respondents have between 18 and 28 years. T - test showed that there were significant statistical differences between the three groups when it comes to fitness index and maximal oxygen consumption.

Students tested in the period from 1997-2000 had higher fitness index than the students tested in subsequent periods. Fitness index of the value of 104.1 in the first group tested falling to 91.1 in the second group tested, and in the third group tested its value was 77.3. In the last generation of students tested, the index value is below the average value of the Swedish population norms, while the index for the first two groups moving average. Speaking of maximum oxygen consumption in men, there is also a trend of decreasing this value. This value was 51.3 for first tested group, falling to 46.1, and in the third $40.8 \mathrm{ml} / \mathrm{kg} / \mathrm{min}$. According to the criteria of the Cooper VO2max values of oxygen consumption in the first and second groups were slightly above average values, while the third group had average value.

For female students there is also a downward trend in the value of Fitness index from 96.4 tested in the first group, to 86.1, in the second group tested, and finally to 84.8 in the third group. This means that only the index of the first group was in range of average values, while the second and third group value is below the average. Maximum oxygen consumption t has a downward trend from 37.5 in the first group, 34 in the second group to 33.7 in the third group tested. VO2max values for females was average range.

The results obtained are showing trend of decreasing aerobic capacity in students of both genders, but the trend is less pronounced decline for female students. The general trend of decreasing aerobic fitness of the population can be seen in the students and faculty staff also. This phenomenon is a consequence of the way of life in which there is not enough adequate physical activity. Concern that the investigation relates to the students of Faculty of Sport and Physical Education, beacuse exercise should be the essence of their interest. The problem may be in the reduction of the material in college (the number of hours of practical training), which is related to physical activity, and reduced students interest in extracurricular or recreational activities. It is important to note that the implementation of the test was at the beginning of the school year, after the exams, when students where ocupied in exam preparation and most of the time during the day they spend in a seated position, which may be the cause of physical inactivity. 


\section{References}

Cvetković, M. (2009). Sportska dijagnostika. Novi Sad: TIMS.

Laukkanen, R., Oja P., Pasanen M., \& Vuori I. (1992). Validity of a two kilometre walking test for estimating maximal aerobic power in overweight adults. Journal of Obesity and Related Metabolic Disorders, 16(4), 263-268.

Mihajlović, N., \& Mitić, D. (2010). Stanje kondicije učesnika na letnjem festivalu rekreacije. U Zbornik radova Čanj 2010 (str. 416-420). Beograd: Fakultet sporta i fizičkog vaspitanja.

Mitić, D. (2001). Rekreacija. Beograd: Fakultet sporta i fizičkog vaspitanja.

Stojiljković, S., Mitić, D., Mandarić, S., \& Nešić, D. (2005). Fitness. Beograd: Fakultet sporta fizičkog vaspitanja. 